Chapman University

Chapman University Digital Commons

Education Faculty Articles and Research

College of Educational Studies

2013

\title{
Culturally Responsive Methodologies at Work in Education Settings
}

Mere Berryman

University of Waikato

Suzanne SooHoo

ChapmanUniversity, soohoo@chapman.edu

Ann Nevin

Arizona State University

Te Arani Barrett

University of Waikato

Therese Ford

University of Waikato

Follow this and additional works at: http://digitalcommons.chapman.edu/education_articles can next page for additional authors

Part of the Bilingual, Multilingual, and Multicultural Education Commons, Curriculum and

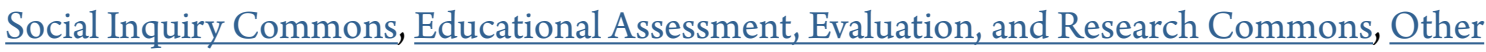
Anthropology Commons, Other International and Area Studies Commons, Other Languages, Societies, and Cultures Commons, Quantitative, Qualitative, Comparative, and Historical Methodologies Commons, Race, Ethnicity and Post-Colonial Studies Commons, $\underline{\text { Social and }}$ Cultural Anthropology Commons, and the Sociology of Culture Commons

\section{Recommended Citation}

Berryman, M., SooHoo, S., Nevin, A., Barrett, T. A., Ford, T., Nodelman, D. J., Valenzuela, N., \& Wilson, A. (2013). Culturally responsive methodologies at work in education settings. International Journal for Researcher Development, 4(2), 102-116. DOI: 10.1108/IJRD-08-2013-0014 


\section{Culturally Responsive Methodologies at Work in Education Settings}

Comments

This is a pre-copy-editing, author-produced PDF of an article accepted for publication in International Journal for Researcher Development, volume 4, issue 2, in 2013. The definitive publisher-authenticated version is available online at DOI: 10.1108/IJRD-08-2013-0014

\section{Copyright}

Emerald

\section{Authors}

Mere Berryman, Suzanne SooHoo, Ann Nevin, Te Arani Barrett, Therese Ford, Debora Joy Nodelman, Norma Valenzuela, and Anna Wilson 
Berryman, M., SooHoo, S., Nevin, A., Barrett, T. A., Ford, T., Nodelman, D. J., Valenzuela, N., \& Wilson, A. (2013). Culturally responsive methodologies at work in education settings. International Journal for Researcher Development, 4(2), 102-116. DOI: 10.1108/IJRD-08-2013-0014

\title{
Culturally responsive methodologies at work in education settings
}

\begin{abstract}
Purpose - The purpose of this paper is to describe culturally responsive methodology as a way to develop researchers. The aim is to illuminate the dimensions of culturally responsive methodology such as cultural and epistemological pluralism, deconstruction of Western colonial traditions of research, and primacy of relationships within culturally responsive dialogic encounters. An overarching question is: "How can we maintain the original integrity of both participants and researchers and their respective cultures and coconstruct at the same time something new?”
\end{abstract}

Design/methodology/approach - Five case study narratives are described in order for readers to understand the range and types of studies that have been undertaken within a culturally responsive framework. The contributors represent emerging as well as veteran researchers, Indigenous as well as non-Indigenous cultures, practitioners (i.e. teachers in the school systems) as well as teacher educators (i.e. that is teachers within colleges and universities).

Findings - The major issues raised in this paper (knowing one's self and being willing to develop new methodologies) can help to inform those who aspire to research "with" rather than "on” Others.

Originality/value - This paper offers an ontology that is not framed from western traditions. Using reflexivity, criticality, and other epistemological links, the authors show methodological negotiators who invent, craft, personalize, and navigate their methodology and methods specific to the context and participants with whom they are working. They challenge unexamined assumptions in research methods. It is hoped that this paper can contribute a more respectful and humble way of working with all peoples.

Keywords - Indigenous and marginalised participants, doctoral students, emerging scholars, faculty mentors, narratives, critical pedagogy, Kaupapa Māori

Paper type - Narrative case studies featuring culturally responsive research methodology aimed at the preparation of new researchers. 
In this paper, we describe a culturally responsive methodology as a way to develop researchers. As dissertation chairs and mentors to doctoral students, four of the authors of this paper worked with four doctoral candidates who agreed to approach their studies with respect, humility, and culturally responsive conceptual frameworks. We wanted to challenge prevailing traditional methodologies that required objectivity when studying "the other". Our life experiences, the people with whom we work and those who have invited us to study with them, all have influenced our decision to follow an organic and relational process of development. We emphasize our commitment to selfinterrogation as researchers, understanding that our own cultures and identities influence the way we seek to undertake research with any community. We describe how we have prepared ourselves for a new research experience using culturally responsive methodology.

\section{Purpose}

We hope to illuminate the dimensions of culturally responsive methodology such as cultural and epistemological pluralism (Biermann 2011), deconstruction of Western colonial traditions of research (Césaire 2000; Freire 1972), and primacy of relationships within culturally responsive dialogic encounters (Bishop, Berryman, Cavanaugh, \& Teddy 2009). An overarching question that guides our work is, "How can we maintain the original integrity of both participants and researchers and their respective cultures and co-construct at the same time something new?”

To do this, we share examples showing how the researcher, with her community, articulated a stance (or subjectivity statement) from which she developed a culturally responsive methodology specific to her unique research questions and population through an organic and relational process. Highly subjective, each researcher described the process of interrogating her own positionality within the field of academia as well as her own research interests. Throughout this process we emphasize the importance of making connections, developing relationships, and understanding the differential power relationships inherent in this work. We tackle questions of what we have done as researchers in order to co-construct new knowledge, to learn, and to make a contribution.

\section{Background}

The authors in this paper represent an academic partnership between staff and students from Chapman University in California, USA and staff and students from the University of Waikato in New Zealand. The authors also represent a partnership of different cultural identities that include Asian-American, Anglo-American, Latina, Lesbian-Bisexual-Gay-Transexual (LBGT), Deaf(Hard of Hearing), and Māori researchers. Education disparities continue to exist for marginalized populations in the United .States. The most egregious example of this disparity is seen in the continued disproportional representation of students with disabilities who come from racially, culturally, and linguistically diverse heritages. Specific data reflecting disproportionate placement of Black and Hispanic students in special education is reported by Harry and Klingner (2005) and over-representation of Hispanic and African-American students in English language learning classes is reported by Sullivan (2011).

Māori are the Indigenous people of New Zealand, a country in the South Pacific that from the early part of the $19^{\text {th }}$ Century was colonized by European settlers. Following colonization and the neo-colonial institutions that subsequently emerged, Māori have been subjected to educational, social, economic and political disparities in their own 
country. Despite a signed Treaty with the Crown that promised to Māori the Crown's protection; that Māori would maintain possession of all that they valued; and that they would participate in the same benefits as their colonial partners, these disparities continue to the present day (Bishop \& Glynn, 1999). Today Māori comprise the largest minority group of just under $15 \%$ of the overall population with $22 \%$ of public school children now being of Māori descent. Although the Māori language is an official language, like many other Indigenous languages, it is threatened, with only just over $4 \%$ of the population able to speak Māori language today. In response to language and other cultural losses, many Māori have begun to contribute to a grass roots movement of language and cultural revitalization over the past four decades. Known as Kaupapa Māori, this movement is aimed at greater self-determination for Māori in all aspects of contemporary New Zealand society.

Education in New Zealand has been characterized by both the ongoing disparities between the academic achievement of Māori) and non-Māori students and the consistent underachievement by Māori students in mainstream school settings. In New Zealand mainstream describes education settings where the medium of instruction is the English language and the curriculm is developed and delivered from within the worldview of the dominant - non-Māori group. Historical failures to address these educational disparities have had devastating outcomes for Māori in the wider context of New Zealand society and these consequences are aptly described by Bishop, O'Sullivan and Berryman (2010):

Māori continue to have higher levels of unemployment, are more likely to be employed in low-paying employment, have much higher levels of incarceration, illness and poverty than do the rest of the population and are generally underrepresented in positive social and economic indicators of society (p. 10). Collectively, it is from these diverse patterns of marginality that we position our work.

\section{Positioning our Work}

We draw mainly upon explanations of critical theory and kaupapa Māori theory, and it is within these two key theoretical frameworks that we position our work. Our work is grounded in Māori metaphor and ways of knowing as three of the co-authors have strong connections with Te Kotahitanga, a school reform programme improving the educational achievement of Indigenous Māori secondary school students in New Zealand and currently operating in 50 secondary schools (Bishop, Berryman, Tiakiwai, \& Richardson 2003). Four of the authors reflect the pedagogical theorizing and practices of decolonizing methodologies (e.g., Denzin, Lincoln, \& Smith, 2008) and the critical pedagogy contributions of Paulo Freire (1972). We acknowledge similar notions of freedom from domination, self determination and relationships are also to be found in postcolonial theory and feminist theory.

Culturally Responsive Methodology Defined

We emphasize that there is no one definition of a culturally responsive methodology; instead we propose that culturally responsive methodology 1) embraces cultural and epistemological pluralism; 2) deconstructs Western colonial traditions of research; and 3) recognizes the primacy of relationships within a power-sharing dialogical encounter (Berryman, SooHoo, \& Nevin, 2013). Culturally responsive methodology encourages the researcher to engage in three distinct and often concurrent phases of the research l) learn to know the participant(s) subjectivities 2) make transparent the researcher's positionality and 3) engage in relational and dialogical 
encounters. Framing these phases are questions of ethics: what right does one have to engage in the study? who will own the research? And who determines the public good of the research?

The work of culturally responsive methodology challenges traditional education research paradigms and honors multiple ways of knowing and engagement. Grounded in critical theory, ethnology, and post-colonial studies, these types of cross- and intracultural research collaborations offer new pathways for the creation of rich educational and social science research. Culturally responsive methodology is both inclusive of many postmodern research methodologies as well as distinctive. Researchers from methodologies such as feminist (Harding 2004), decolonizing (Denzin, Lincoln, \& Smith 2008; Mutua \& Swadener 2004), participatory (Anderson, Herr, \& Niblen 2007), and public sociology (Buroway 2005) come from different histories, use different language, and ultimately have similar approaches: those that aim to bring those who have been marginalised to the center of research as co-constructors.

Culturally responsive methodology differs from feminist methodologies in its broad interpretation of culture as a cornerstone although it has a similar emphasis on relationships, reciprocity, and community. It shares the same resistance to hierarchical power structures but differs from decolonizing methodologies--culturally responsive methodology recognizes oppressor/oppressed relationships are not all rooted in colonizing histories (e.g., special needs populations). Culturally responsive methodology shares the same goal of involving all stakeholders in the research as in participatory research and public sociology but differs in intention--culturally responsive methodology is not always about change and transformation. In culturally responsive methodology, one does not enter the relationship with the explicit intention of changing the other but rather to honor and support the other. Moreover, culturally responsive methodology offers an alternative approach for emerging scholars and provides them with ethical foundations and the freedom to craft culturally-specific methods informed by the dialogical relationship.

\section{Five Personal Narratives}

In this article, five case study narratives are described in order for readers to understand the range and types of studies that have been undertaken within a culturally responsive framework. We focus on the self-interrogation of one's self as researchers as we embark on the ritual of encounter with the Other with whom we wish to study. The contributors represent emerging as well as veteran researchers, Indigenous as well as non-Indigenous cultures, practitioners (i.e., teachers in the school systems) as well as teacher educators (i.e., that is teachers within colleges and universities).

Wilson (2013), a veteran researcher, tackled the issue of naming others by posing the question "How do you know they are lesbians?" The conundrum of naming continued to frame her research although it no longer framed her life or her identity. She has become quite comfortable with locatingher identity as a lesbian, a Jew, a feminist. She explained that her identity is composed of three areas and those three areas are never omitted. This grounding of self secures her to her work, her scholarship, her being. To the question of what does a lesbian look like, Wilson (2013) wrote, "We look like straight people; we come in all colors, all sizes, all shapes, all classes, all educational levels, all professions (and now we are 'out' in the U. S. military). We are grandparents, parents, sisters, mothers, aunts, daughters; we are judges, lawyers, teachers, professors, 
waitresses, students, domestics, pilots, flight attendants, police officers, fire(wo)men, authors, and more. Therefore, in one sense, we are like everyone else, but in a very different sense, we are not. We have our own culture, our own language, and our own community because we have been oppressed over time and needed to build a safe place for us to be ourselves" (p. 246). Though societal acceptance of non-heteronormativity is changing and evolving, she noted that if one wants to 'do research' in a lesbian community; then one must engage in thoughtful methodological conversations with this community, working to build a relationship of understanding with those participating in the research. She explored the implications of thoughtful methodological conversations within the lesbian community, explaining that identifying herself as a lesbian is not just a personal statement, but also a political one. However, the researcher's responsibility is to engage in reflexive methodological practices so as not to place participants in untenable positions. By constantly problematizing power differentials often inherent between researchers and study participants, she was able to remain open to reflexive turns within her own research paradigm. This attitude of being aware of the responsibilities is a cornerstone of a culturally responsive methodologist. To be aware of one's personal status, to be aware of oneself as both insider and outsider, facilitates our research, but it is not ours. This belongs to all of us who identify as culturally responsible, culturally responsible methodologists

Valenzuela (2013) wanted to empower Latina women by deconstructing love as a way of knowing. As an emerging scholar, she delineated the process by which she came to understand and know herself, her own identity, her place in this world, and finding her own voice. Her account, written in both Spanish and English, represents a vivid confession of the transformations that occurred as she moved from being a doctoral student to becoming a culturally responsive researcher. Her narrative may influence others who have struggled to understand themselves before going out into the field of research and serves as an example of someone who has learned to be comfortable with herself, someone who has come to understand that she has something of value to bring to the table, and someone whose unique experience can help other beginning researchers undergoing a similar journey. Within culturally responsive and socially responsible methodology, understanding one's self before understanding others is the first step toward building relationships based on mutual respect. She asks, "How can one really know her self, her purpose, and her reasons for wanting to conduct a study?” She argued that conducting the traditional Western research characterized by the researcher coming in as an outsider simply observing participants without participating him/herself could be a lot easier than developing a culturally responsive methodology. Instead, she asked, "What gives me the right to study other Latino students?" The fact that she is a Mexican woman who grew up in the same community that she now teaches in does not earn her the right to conduct research with that community. She asked whether her role is primarily as an insider or an outsider, or both? If so, what qualities does she have that afforded her this luxury of being an insider? What qualities does she have that reflected the perception of herself as an outsider? And finally, Valenzuela asked, "Who cares about my work?" and "Why is my work important?"

Ford (2013) sought to contribute to a new education story for Māori. She asked, "What would an education that enabled Māori students to achieve education success as Māori actually look like in practice?" Her findings link culturally responsive 
methodologies to curriculum studies. In describing her research journey she traces the history, throughout the past four decades, of how the dominant members of New Zealand society have expressed concerns about the low educational achievement levels of Māori students compared with non- Māori (Bishop, Berryman, Taikiwai, \& Richardson, 2003; Bishop \& Glynn, 1999). In 1991 Graham Hingangaroa Smith referred to this situation as the "Māori educational crisis" (p. ii). Addressing these achievement disparities is a major government priority in New Zealand and is identified by the Ministry of Education as being a critical challenge for school leadership (Ministry of Education, 2008). In line with Freire (1972) and his famous proposition about the potential of marginalised populations to free themselves from oppression, Smith (1991) and others (Bishop, 1996; 2011; Bishop \& Glynn, 1999) contend that solutions for the "Māori educational crisis" can be found within kaupapa Māori contexts such as kaupapa Māori educational settings and research. Ford traces her personal journey as a Māori student, teacher and school leader, as a mother of two Māori children and as an aspiring kaupapa Māori researcher seeking to work in culturally responsive ways. She started with the background story of the New Zealand education policy context and provided the platform to explain the personal narrative that is her own story, of the sad impact mainstream education has had over four generations of her own family. As she stated, "My own story informs what I want and expect for my own children and all future generations of Māori children and these aspirations have been the catalyst for me to engage in kaupapa Māori research. Her goal is to make a contribution to the development of pedagogies that will enable Māori students to enjoy education success as Māori. Unlike her grandmother whose education reflected assimilation policy and as a Māori student was required to leave her culture at the school-house gate, she traces the emerging experiences of her daughter as she is allowed to bring her culture to her classroom. The new story, Author 3 emphasizes, is mirrored in her own journey as she seeks to understand, evolve and work to become a culturally responsive and socially responsible researcher.

Barrett (2013) described her emergent researcher role in her study of Māori tribal elders entitled, “The river is me and I am the river. Principles for the organic Māori researcher”. She highlighted indigenous research methodology as being culturally responsive and responsible to the lores of the land and describes a methodology for 'coming to know' from Māori tribal elders by looking at her unique cultural epistemology and engaging with cultural leaders. The richness of the knowledge of each elder was demonstrated across a range of settings. Recalling what was observed, heard and experienced within our own territories, and the territories of others, over time, are privileged opportunities to be honoured. Understandings from the research interactions that have occurred over time, and since narratives are a culturally appropriate means of sharing knowledge, their stories are in turn represented through narratives. Barrett also ensured that she observed tribal protocol in how the knowledge was gathered, valued and represented; she believed that being aware of and keeping tribal protocol was an indicator of her cultural responsiveness.

Nodelman (2013) discovered how to elicit the voices of elementary children as part of the research journey for her study. She likened her experience to that of experiencing a river aesthetically - that is, appreciating one of nature's gifts. Yet, she cautions, those familiar with rivers know that challenges may lie submerged below the water. Many times one is not aware of forces beneath the surface; strong, hidden currents 
that push and pull with surprising strength and may render the unsuspecting helpless against its powerful movements. Like the river, a culturally responsive qualitative study will include facing the sometimes unseen dilemmas inherent in research. Nodelman posed a powerful inquiry question to guide the study: How do children describe their experience and process of meaning-making through the visual arts in the space of an elementary visual art studio? She related how her identity as a social justice educator and artist impacted the work with students. She discussed two continuing challenges: a) integrating the principles of culturally responsive methodology and b) structuring the visual arts studio in a way that was culturally responsive to school-age participants by coconstructing a space where students came to new understandings about themselves, their families, and their community. A monolingual English speaker in a classroom of bilingual (Spanish/English) children, she interrogated her own ways of engaging with young participants using a culturally responsive methodology. From her experiences developing the methodology, readers may learn that routine thinking and routine qualitative methods may not fit the research one plans to conduct. Culturally responsive methodologies brought her the freedom to craft a methodology that worked in a unique cultural context. Unexpectedly, transformative possibilities of a curriculum in the arts emerged. For example, she and the children both developed an 'art worker' identity; and connections to their families were developed in deeper ways. The students' attitudes about art changed-- they began to understand art does not just exist in the museums. They developed an awareness that art was in their homes as well as in their classroom studio environment. Culturally responsive methodologies liberated the researcher and the students to distinguish and discover the cultural capital known as art as inherently a part of the Latino community as well in high culture museums.

\section{Discussion}

To guide this discussion, Table 1 shows the key messages derived from the case study narratives: linking to earlier research, critically interrogating our own ways of knowing resisting traditional ways of doing research; and reframing researcher bias as unique subjectivities; being transparent in researcher positionality, and valuing the participants and one's invitation to do research. The narratives characterized dispositions that empower completion of phase 2 of the research process - making transparent the positionality of the researcher. Each is discussed below.

\section{Table 1. Key Messages from the Narratives}

Linking to previous research
Critically interrogating our own ways of knowing
Resisting traditional ways of doing research
Reframing researcher bias as unique subjectivities
Valuing the participants and one’s invitation to do
research


Nevin links these five case study narratives to earlier research that reflects culturally responsive and socially responsible approaches that are being reported and discussed in various venues (Arzubiaga, Artiles, King, \& Harris-Murri 2008; Calamaro 2008; Tillman 2002; Trainor 2011). However, our work, as reflected in these five case study narratives, differs in significant ways. For example, Calamaro (2008) argued that bi-culturally competent researchers are recommended when study participants are drawn from bi-cultural populations. In contrast, our work relies on the principle that this is essential, although we have found that culturally competent outsiders can accompany cultural insiders on research projects. Similar to Trainor (2011) who argued that situated cultural practice should guide research in special education; we recognize the importance of culturally responsive methods for evaluating research. For example, we agree that a) the review of the literature should include those that "employ alternative methodologies and perspectives on the research problem” (Trainor, 2012, p. 12); b) descriptions of participants AND the researchers should include individual characteristics and contextualized institutional dimensions such as power and status; c) rationales for (multiple) data collection strategies should include consideration of cultural and linguistic preferences, needs, and strengths as well as descriptions of the interactions between researchers and participants. We note that merely belonging to the cultural group does not mean that one has not already been educated in and operating within the dominant hegemonic colonial discourses. The unlearning of dominant research practices and relearning methodology through and with research participants inform the mutual identity formations between the researcher and the researched which is a phenomenon found also in Tillman (2002). By employing culturally responsive methodologies, authors of the case study narratives in this paper have reframed the concept of researcher bias as a gift in which researchers bring their own "unique subjectivities" to any project. The intersection of their subjectivities becomes a lens through which to examine the narrative.

Berryman noted that the five case study narratives represented a context of disputed territories, and that culturally responsive methodologies can offer examples of resistance to the traditional ways of doing research. Specifically, Barrett shared who she is in cultural terms which, in turn, defined how she conducted herself as a culturally responsive researcher. She was guided in her research by looking at cultural epistemology as she engaged in discourses with cultural leaders. Through her research we will all benefit from her stories. In contrast, Ford began her story of a hundred rivers, a story of renaming and othering through colonization and then reclaiming the names and in so doing reclaiming themselves as Māori. Although her chapter was set in the context of the negative educational indices for Māori in New Zealand, she challenged the notion of Māori students enjoying education as Māori, an aspiration she has for her children. Valenzuela described how she found clarity amongst murky water and empowering Latina women. Valuing an emotional dimension is also reflected in the way that Valenzuela used the term "love" as the root of all that we do and maintains it should be at the root of our relationships as researchers. Her vivid description of the transformation that she is undergoing as she comes to understand this researcher role, she acknowledged that she was an insider as well as an outsider and is emerging with a strong voice as a culturally responsive researcher. Wilson explored the questions of naming and identifying. We believe that starting with the question of identity, her own and others, our 
own, and those with whom we all seek to engage with research is the first step in conducting a quality culturally responsive study. "How do you know?" is as challenging a question as "How do you not know?" And on the basis of how you know or not know, how do you name? What does this mean for self, and what does this mean for others with whom we seek to relate and engage? And what are the implications when we seek to undertake research?

SooHoo emphasized how the case study narratives are connected in significant ways. They were transparent about the kinds of histories that we bring forward that inform our research. Such histories are not typically transparent in research studies or doctoral dissertations. A researcher's transparency is an offering of honor and respect to the participants and acknowledges the invitation to do research with them. For example, Barrett explained how her respectful tribal point of view and all the roles she deeply investigated to find a pathway in the work she does. Ford valued the role of history to inform the present and our future by tracing the personal stories of her grand-mother (educated in colonial times), her mother, her self, and her daughter (now benefiting from the new story of being educated as Māori). Nodelman's powerful and meaningful application of culturally responsive methodologies represented political resistance to the crises of the current national context obsessed with standardized testing,. By making space for meaning, creating a curriculum of meaning-making for children to learn art as an alternative language for expressing what they know, Nodelman extended the boundaries of typical dissertation research. Valenzuela reaffirmed love as the energy that is central to our work and echoes Paulo Freire's legacy. Wilson, similar to all of our contributors, .highlighted her vulnerability as a lesbian academic which she freely shared with us. As she holds those reflections up to all to see, we recognize the intersectionality of our subjectivities like the tributaries along the river connecting the margins to the mainstream.

SooHoo asserts the research process is like a river, it is never still; instead it is dynamic and ever changing. In the beginning of our journeys as culturally responsive researchers, we formulate our understandings of how to ethically and respectfully approach communities so that we are working with them and not on them. We suggest that as researchers begin to craft their methods, they must begin by being in relationships with people, establishing and being very carefully attuned to what would be culturally sensitive and not to replicate the gazing anthropological studies which view the "other", the savages. Our contributors emphasized that this kind of inquiry starts where the river was unclear and some of our contributors tentatively walked into the river or splashed, or said, "I just must get wet here." In these narratives, we experience how each of us has emerged from the inquiry process with clearer definitions of what we ought to be doing, and, at the same time, we found some answers about how we can be culturally responsive. ,Because a river is not a still pond, the river will continue only if it is dynamic. In other words, we must routinely question and contest our work and our ways of knowing. Emerging and veteran researchers must ask how they will critically interrogate cultural responsive methodologies as well as traditional models of research. It is in this commitment to criticality that we enter the cycle of research. Criticality like the river through the research process like the river moves out to the ocean. Criticality transforms into possibility like the river evaporates back into the atmosphere. Criticality 
informs the reiterative cycle of learning within the research process like the sky feeds the mountain tops that bring the river down to nourish us.

\section{Implications}

In addition to the implications for curriculum discussed above, two other implications are discussed in this section: using culturally responsive methods to undertake collaborative participatory inquiry and preparing the next generation of scholars and stewards of the educational research discipline, Most members of this international team of scholars and emerging scholars come from minoritized groups (Shields, Bishop, \& Mazawi, 2005) from all parts of the globe, including many who are Indigenous. Like Shields et al., we also emphasize that whether colonized or not, many of these minoritized groups are subjected to oppression and suppression by conditions of the dominant discourse, in that they continue to be excluded from decision-making and other positions of power. Other members of this international team of scholars recognize the privileged social positions from which they may have emerged and critically reflected upon how they can contribute to the research using their cultural capital towards a more collaborative non-dominating and interdependent stance. Together we have found how deficit theorizing perpetuates the culture of intellectual poverty and therefore have sought research designs and methods framed by cultural strengths, respect for Others, and social responsibility.

We offer culturally responsive research methodologies as a way of undertaking more collaborative and participatory inquiry. In this paper, we described how researchers had to resist traditional paradigms and epistemologies as they learned and then practiced culturally responsive methodologies. For example, Barrett, Ford, and Nodelman showed how their research practices were influenced by the knowledge, values, and advice of community elders, Examining the place and responsibilities of elders within the profession as well as the community becomes a paramount focus of the researcher who works within a culturally responsive methodology. We believe that a culturally responsive research process begins by understanding one's own identity and the discourses within which one is positioned. We hope our readers learned how we both challenged western paradigms and developed methodologies that required the researcher to develop relationships that enabled them to intimately come to respect and know the "Other" with whom they sought to study. This may only begin to happen when such a relationship is reciprocated. Such a stance challenges traditional research notions of distanced objectivy and neutrality, opening up instead streams of research that call for engagement through the establishment of relational discourses. Addressing major issues such as knowing one's self and being willing to develop new methodologies in direct response to the humanity of the participants can help to inform those who are researching "with” rather than "on” Others. In describing how they found discovered, and invented methodology that benefits both from their insider knowledge and from the epistemology of others, our contributors show they were informed by the work and scholarship of critical studies and Indigenous researchers, both nationally and internationally. Moreover, we have realized culturally responsive methodologies may be a more socially responsible position from which to navigate the research process. We have learned that one should not study movements of culturally self-determined peoples without culturally responsive 
research methodologies or without the active engagement of the participants in the research process.

A culturally responsive methodology stimulates doctoral students towards a collaboratively developed discursive position, an ideological shift towards epistemological multilogicality, as a result of relationship and dialogue with participants (Berryman et al., 2013). Barrett, Ford, Nodelman, Valenzuela, and Wilson each situated their studies within the cultural contexts of their participants and collaboratively adjusted research methods to adapt to participants' preferred cultural ways of knowing. By showcasing the work of doctoral students in various stages of their doctoral programme, we make visible that expertise comes from sincere doctoral students as learners who are new to research and, as evidenced by their narratives, they show how they maintained an open, respectful stance when studying with others. The authors, both emerging and veteran scholars, agreed that they have an ethical responsibility to consider how to engage in research where agendas, protocols, and benefits are collaboratively determined on culturally determined terms. A critical consideration of our own discursive positioning is needed in culturally responsive research if we are to ensure participatory and/or liberatory discourses that will promote new potential. The paper represents a unique collaboration amongst an international team of authors who are experienced educators, teacher educators, and/or doctoral students from many disciplines (e.g., special education, disabilities studies, multicultural studies, critical pedagogy, linguistics and language learning, lesbian studies, etc). This undertaking can provide another of a growing list of examples of emerging and veteran scholars who interrogate their work together (for another example, see Howard-Hamilton, Morelon-Quainoo, Johnson, Winkle-Wagner, \& Santiague 2009, and SooHoo, 2012).

We hope to find other scholars who understand the importance of epistemological clarity and reflexivity throughout all phases of the study and use their researcher's power for the good of others. We hope that a culturally responsive methodology can yield a more transformative praxis that results in more socially just outcomes for marginalized groups. From the relational, power sharing and responsive, dialogic methods described by the narratives, we have all learned much but also understand that from within these contexts, there is still -much that we can learn. Informed by the theories and scholarship of critical and indigenous researchers, culturally responsive research methodologies offer an alternative position from which to develop future researchers that is characterized by relationships, subjectivity, co-construction, and mutual good. Being a researcher is being with people. 


\section{References}

Anderson, G. L., Herr, K., \& Nihlen, A. S. (2007). Studying your own school: An educator's guide to practitioner research. Thousand Oaks, CA: Corwin Press.

Arzubiaga, A., Artiles, A., King, K., \& Harris-Murri, N. (2008). Beyond research on cultural minorities: Challenges and implications of research as situated cultural practice. Exceptional Children, 74, 309-327.

Barrett, T. A. (2013). The river is me and I am the river: Principles for the organic Māori researcher. In Berryman, M., SooHoo, S., \& Nevin, A. (Eds.). Culturally responsive methodologies (pp. 221 - 244). Bingley, UK: Emerald Group Publishing.

Berryman, M., SooHoo, S., \& Nevin, A. (2013, Eds.) Culturally responsive methodologies. Bingley, UK: Emerald Group Publishing.

Biermann, S. (2011). Knowledge, power and decolonization: Implications for nonIndigenous scholars, researchers, and educators. In Dei, G. (Ed), Indigenous philosophies and critical education (pp. 386-398) New York, NY: Peter Lang Publishing.

Bishop, R. (1996). Collaborative research stories: Whakawhanaungatanga. Palmerston North, NZ: Dunmore Press.

Bishop, R. (2011). Freeing ourselves. Rotterdam, Netherlands: Sense Publishing.

Bishop, R., Berryman, M. Tiakiwai, S., \& Richardson, C. (2003). Te Kotahitanga: The experiences of year 9 and 10 Màori students in mainstream classrooms. Wellington, NZ: Ministry of Education.

Bishop, R., Berryman, M., Cavanagh, T., \& Teddy, L. (2009).Te Kotahitanga: Addressing educational disparities facing Māori students in New Zealand. Teaching and Teacher Education: An International Journal of Research and Studies, 25(5), 734-742.

Bishop, R., \& Glynn, T. (1999). Culture counts: Changing power relations in education. Palmerston North, NZ: Dunmore Press.

Bishop, R., O'Sullivan, D., \& Berryman, M. (2010). Scaling up education reform: Addressing the politics of disparity. Wellington, NZ: New Zealand Council for Educational Research Press

Burawoy, M. (2005). The 2004 American Sociological Association Presidential address: For public sociology. American Sociological Review, 70(1), 4-28.

Calamaro, C. J. (2008, Sept./Oct.). Cultural competence in research: Research design and subject recruitment. Journal of Pediatric Health Care, 21(5), 329-333.

Césaire, A. (2000). Discourse on colonialism. (J. Pinkham, Transl.). New York, NY: Monthly Review Press.

Denzin, N., Lincoln, Y., \& Smith, L. T. (2008). Handbook of critical and indigenous methodologies. Thousand Oaks, CA: Sage Publications, Inc.

Freire, P. (1972). Pedagogy of the oppressed. New York, NY: Continuum.

Ford, T. (2013). My research journey: Contributing to a new education story for Maori. In Berryman, M., SooHoo, S., \& Nevin, A. (Eds.). Culturally responsive methodologies (pp. 87-106). Bingley, UK: Emerald Group Publishing.

Harding, S. (Ed., 2004). The feminist standpoint theory reader: Intellectual \& political controversies. New York, NY: Routledge. 
Harry, B., \& Klingner, J. (2005). Why are so many minority students in special education? Understanding race \& disability in schools. New York, NY: Teachers College Press.

Howard-Hamilton, M. F., Morelon-Quainoo, C. L., Johnson, S. D., Winkle-Wagner, R., \& Santiague, L. (Eds., 2009), Standing on the outside looking in: Underrepresented students' experiences in advanced degree programmes, Sterling, VA, Stylus Publishing, LLC.

Ministry of Education. (2008). Ka Hikitia: Managing for success Māori education strategy. Wellington, NZ: Ministry of Education.

Mutua, K., \& Swadener, B.B. (Eds., 2004). Decolonizing research in cross-cultural contexts. New York, NY: State University of New York Press.

Nodelman, D. J. (2013). Culturally responsive methodology within an aesthetic framework. In Berryman, M., SooHoo, S., \& Nevin, A. (Eds.). Culturally responsive methodologies (pp.149-174). Bingley, UK: Emerald Group Publishing.

Shields, C., Bishop, R., \& Mazawi, A. E. (2005). Pathologizing practices: The impact of deficit thinking on education. New York: Peter Lang Publishing.

Smith, G. H. (1991). Reform and Maori educational crisis: A grand illusion. Paper presented at the Post Primary Teachers Association Curriculum Conference, Christchurch, May 1991. Retrieved October 6, 2013, from http://www.kaupapamaori.com/assets/Smith,\%20G/reform_and_maori_educational_c risis.pdf

SooHoo, S. (2012). Afterword In Monzo, L. \& Merz, A. (Eds). Public identity and equity action in education. New York, NY: Lang Publishing.

Sullivan, A. (2011). Disproportionality in special education identification and placement of English language learners. Exceptional Children, 77(3), 317-334.

Tillman, L. C. (2002). Culturally sensitive research approaches: An African-American perspective. Educational Researcher, 31(9), 3-12.

Trainor, A. A., \& Bal, A. (2012). Development and preliminary analysis of a rubric for culturally responsive research. Journal of Special Education, doi: http://sed.sagepub.com/content/early/2012/02/24/0022466912436397.abstract?rss=1

Valenzuela, N. (2013). Finding clarity amidst murky waters: Beginnings of a culturally responsive researcher. In Berryman, M., SooHoo, S., \& Nevin, A. (Eds.). Culturally responsive methodologies (pp. 6 9-86). Bingley, UK: Emerald Group Publishing.

Wilson, A. N. (2013). Errant wanderings amongst the voices on the margins. In Berryman, M., SooHoo, S., \& Nevin, A. (Eds.). Culturally responsive methodologies (pp. 245- 262). Bingley, UK: Emerald Group Publishing. 